4

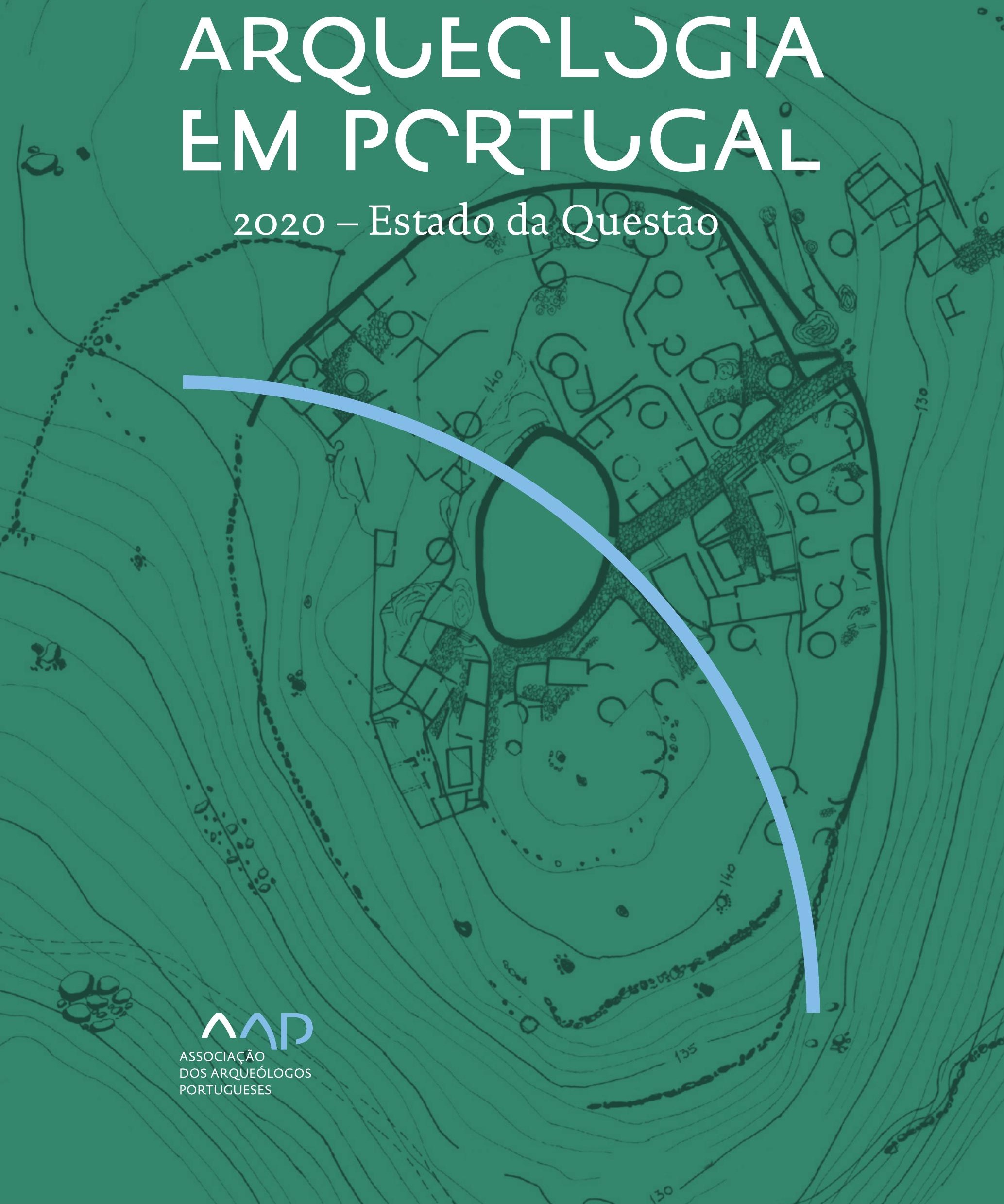


Coordenação editorial: José Morais Arnaud, César Neves e Andrea Martins Design gráfico: Flatland Design

AAP - ISBN: 978-972-9451-89-8

CITCEM - ISBN: 978-989-8970-25-1

Associação dos Arqueólogos Portugueses e CITCEM

Lisboa, 2020

O conteúdo dos artigos é da inteira responsabilidade dos autores. Sendo assim a Associação dos Arqueólogos Portugueses declina qualquer responsabilidade por eventuais equívocos ou questões de ordem ética e legal.

Desenho de capa:

Planta do castro de Monte Mozinho (Museu Municipal de Penafiel).

\section{$\hat{\wedge} \mathrm{P}$}

DOS ARQUEÓLOGOS PORTUGUESES

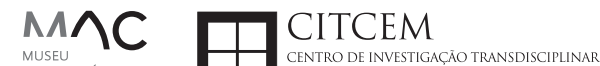
MUSEU
ARQUELLÓGICO
DO CARMO
U.PORTO

FLUP FACULDADE DE LETRAS
UNIVERSIDADE DO PORTO

Apoio

EC para a Ciência 


\section{Índice}

15 Prefácio

José Morais Arnaud

\section{Historiografia e Teoria}

17 Território, comunidade, memória e emoção: a contribuição da história da arqueologia (algumas primeiras e breves reflexões)

Ana Cristina Martins

25 Como descolonizar a arqueologia portuguesa?

Rui Gomes Coelho

41 Arqueologia e Modernidade: uma revisitação pessoal e breve de alguns aspetos da obra homónima de Julian Thomas de 2004

Vítor Oliveira Jorge

57 Dados para a História das Mulheres na Arqueologia portuguesa, dos finais do século XIX aos inícios do século XX: números, nomes e tabelas

Filipa Dimas / Mariana Diniz

73 Retractos da arqueologia portuguesa na imprensa: (in)visibilidades no feminino

Catarina Costeira / Elsa Luís

85 Arqueologia e Arqueólogos no Norte de Portugal Jacinta Bugalhão

101 Vieira Guimarães (1864-1939) e a arqueologia em Tomar: uma abordagem sobre o território e as gentes

João Amendoeira Peixoto / Ana Cristina Martins

115 Os memoráveis? A arqueologia algarvia na imprensa nacional e regional na presente centúria (2001-2019): características, visões do(s) passado(s) e a arqueologia

enquanto marca

Frederico Agosto / João Silva

129 A Evolução da Arqueologia Urbana e a Valorização Patrimonial no Barlavento Algarvio: Os casos de Portimão e Silves

Artur Mateus / Diogo Varandas / Rafael Boavida

\section{Gestão, Valorização e Salvaguarda do Património}

145 O Caderno Reivindicativo e as condições de trabalho em Arqueologia Miguel Rocha / Liliana Matias Carvalho / Regis Barbosa / Mauro Correia / Sara Simões / Jacinta Bugalhão / Sara Brito / Liliana Veríssimo Carvalho / Richard Peace / Pedro Peça / Cézer Santos

155 Os Estudos de Impacte Patrimonial como elemento para uma estratégia sustentável de minimização de impactes no âmbito de reconversões agrícolas Tiago do Pereiro

165 Salvaguarda de Património arqueológico em operações florestais: gestão e sensibilização Filipa Bragança / Gertrudes Zambujo / Sandra Lourenço / Belém Paiva / Carlos Banha / Frederico Tatá Regala / Helena Moura / Jacinta Bugalhão / João Marques / José Correia / Pedro Faria / Samuel Melro

179 Os valores do Património: uma investigação sobre os Sítios Pré-históricos de Arte Rupestre do Vale do Rio Côa e de Siega Verde José Paulo Francisco 
189 Conjugando recursos arqueológicos e naturais para potenciar as visitas ao Geoparque Litoral de Viana do Castelo (Noroeste de Portugal)

Hugo A. Sampaio / Ana M.S. Bettencourt / Susana Marinho / Ricardo Carvalhido

203 Áreas de Potencial Arqueológico na Região do Médio Tejo: Modelo Espacial Preditivo Rita Ferreira Anastácio / Ana Filipa Martins / Luiz Oosterbeek

223 Património Arqueológico e Gestão Territorial: O contributo da Arqueologia para a revisão do PDM de Avis

Ana Cristina Ribeiro

237 A coleção arqueológica do extinto Museu Municipal do Porto - Origens, Percursos e Estudos

Sónia Couto

251 Valpaços - uma nova carta arqueológica

Pedro Pereira / Maria de Fátima Casares Machado

263 Arqueologia na Cidade de Peniche

Adriano Constantino / Luís Rendeiro

273 Arqueologia Urbana: a cidade de Lagos como caso de Estudo Cátia Neto

285 Estratégias de promoção do património cultural subaquático nos Açores. O caso da ilha do Faial

José Luís Neto / José Bettencourt / Luís Borges / Pedro Parreira

297 Carta Arqueológica da Cidade Velha: Uma primeira abordagem

Jaylson Monteiro / Nireide Tavares / Sara da Veiga / Claudino Ramos / Edson Brito /

Carlos Carvalho / Francisco Moreira / Adalberto Tavares

311 Antropologia Virtual: novas metodologias para a análise morfológica e funcional Ricardo Miguel Godinho / Célia Gonçalves

\section{Didáctica da Arqueologia}

327 Como os projetos de Arqueologia podem contribuir para uma comunidade culturalmente mais consciente Alexandra Figueiredo / Claúdio Monteiro / Adolfo Silveira / Ricardo Lopes

337 Educação Patrimonial - Um cidadão esclarecido é um cidadão ativo! Ana Paula Almeida

351 A aproximação da Arqueologia à sala de aula: um caso de estudo no $3^{\circ}$ ciclo do Ensino Básico Luís Serrão Gil

363 Arqueologia 3.o - Pensar e comunicar a Arqueologia para um futuro sustentável Mónica Rolo

377 “Conversa de Arqueólogos" - Divulgar a Arqueologia em tempos de Pandemia Diogo Teixeira Dias

389 Escola Profissional de Arqueologia: desafios e oportunidades Susana Nunes / Dulcineia Pinto / Júlia Silva / Ana Mascarenhas

399 Os Museus de Arqueologia e os Jovens: a oferta educativa para o público adolescente Beatriz Correia Barata / Leonor Medeiros

411 O museu universitário como mediador entre a ciência e a sociedade: o exemplo da secção de arqueologia no Museu de História Natural e da Ciência da Universidade do Porto (MHNC-UP)

Rita Gaspar 
421 Museu de Lanifícios: Real Fábrica de Panos. Atividades no âmbito da Arqueologia Beatriz Correia Barata / Rita Salvado

427 Arqueologia Pública e o caso da localidade da Mata (Torres Novas) Cláudia Manso / Ana Rita Ferreira / Cristiana Ferreira / Vanessa Cardoso Antunes

431 Do sítio arqueológico ao museu: um percurso (também) didático Lídia Fernandes

447 Estão todos convidados para a Festa! E para dançar também... O projecto do Serviço Educativo do Museu Arqueológico do Carmo na $5^{\underline{a}}$ Edição da Festa da Arqueologia Rita Pires dos Santos

459 O “Clã de Carenque”, um projeto didático de arqueologia Eduardo Gonzalez Rocha

469 Mediação cultural: peixe que puxa carroça nas Ruínas Romanas de Troia Inês Vaz Pinto / Ana Patrícia Magalhães / Patrícia Brum / Filipa Santos

481 Didática Arqueológica, experiências do Projeto Mértola Vila Museu Maria de Fátima Palma / Clara Rodrigues / Susana Gómez / Lígia Rafael

\section{Arte Rupestre}

497 Os inventários de arte rupestre em Portugal Mila Simões de Abreu

513 O projeto FIRST-ART - conservação, documentação e gestão das primeiras manifestações de arte rupestre no Sudoeste da Península Ibérica: as grutas do Escoural e Maltravieso Sara Garcês / Hipólito Collado / José Julio García Arranz / Luiz Oosterbeek / António Carlos Silva / Pierluigi Rosina / Hugo Gomes / Anabela Borralheiro Pereira / George Nash / Esmeralda Gomes / Nelson Almeida / Carlos Carpetudo

523 Trabalhos de documentação de arte paleolítica realizados no âmbito do projeto PalæoCôa André Tomás Santos / António Fernando Barbosa / Luís Luís / Marcelo Silvestre / Thierry Aubry

537 Imagens fantasmagóricas, silhuetas elusivas: as figuras humanas na arte do Paleolítico Superior da região do Côa Mário Reis

$55^{1}$ Os motivos zoomórficos representados nas placas de tear de Vila Nova de São Pedro (Azambuja, Portugal) Andrea Martins / César Neves / José M. Arnaud / Mariana Diniz

571 Arte Rupestre do Monte de Góios (Lanhelas, Caminha). Síntese dos resultados dos trabalhos efectuados em 2007-2009 Mário Varela Gomes

599 Gravuras rupestres de barquiformes no Monte de S. Romão, Guimarães, Noroeste de Portugal Daniela Cardoso

613 Círculos segmentados gravados na Bacia do Rio Lima (Noroeste de Portugal): contributos para o seu estudo Diogo Marinho / Ana M.S. Bettencourt / Hugo Aluai Sampaio

631 Equídeos gravados no curso inferior do Rio Mouro, Monção (NW Portugal). Análise preliminar Coutinho, L.M. / Bettencourt, A.M.S / Sampaio, Hugo A.S

645 Paletas na Arte Rupestre do Noroeste de Portugal. Inventário preliminar Bruna Sousa Afonso / Ana M. S. Bettencourt / Hugo A. Sampaio 


\section{Pré-História}

661 O projeto Miño/Minho: balanço de quatro anos de trabalhos arqueológicos Sérgio Monteiro-Rodrigues / João Pedro Cunha-Ribeiro / Eduardo Méndez-Quintas / Carlos Ferreira / Pedro Xavier / José Meireles / Alberto Gomes / Manuel Santonja / Alfredo Pérez-González

677 A ocupação paleolítica da margem esquerda do Baixo Minho: a indústria lítica do sítio de Pedreiras 2 (Monção, Portugal) e a sua integração no contexto regional Carlos Ferreira / João Pedro Cunha-Ribeiro / Sérgio Monteiro-Rodrigues / Eduardo Méndez-Quintas / Pedro Xavier / José Meireles / Alberto Gomes / Manuel Santonja / Alfredo Pérez-González

693 O sítio acheulense do Plistocénico médio da Gruta da Aroeira Joan Daura / Montserrat Sanz / Filipa Rodrigues / Pedro Souto / João Zilhão

703 As sociedades neandertais no Barlavento algarvio: modelos preditivos com recurso aos SIG

Daniela Maio

715 A utilização de quartzo durante o Paleolítico Superior no território dos vales dos rios Vouga e Côa

Cristina Gameiro / Thierry Aubry / Bárbara Costa / Sérgio Gomes / Luís Luís / Carmen Manzano / André Tomás Santos

733 Uma perspetiva diacrónica da ocupação do concheiro do Cabeço da Amoreira (Muge, Portugal) a partir da tecnologia lítica Joana Belmiro / João Cascalheira / Célia Gonçalves

745 Novos dados sobre a Pré-história Antiga no concelho de Palmela. A intervenção arqueológica no sítio do Poceirão I

Michelle Teixeira Santos

757 Problemas em torno de Datas Absolutas Pré-Históricas no Norte do Alentejo Jorge de Oliveira

771 Povoamento pré-histórico nas áreas montanhosas do NO de Portugal: o Abrigo 1 de Vale de Cerdeira Pedro Xavier / José Meireles / Carlos Alves

783 Apreciação do povoamento do Neolítico Inicial na Baixa Bacia do Douro. A Lavra I (Serra da Aboboreira) como caso de estudo Maria de Jesus Sanches

797 O Processo de Neolitização na Plataforma do Mondego: os dados do Sector C do Outeiro dos Castelos de Beijós (Carregal do Sal)

João Carlos de Senna-Martinez / José Manuel Quintã Ventura / Andreia Carvalho / Cíntia Maurício

823 Novos trabalhos na Lapa da Bugalheira (Almonda, Torres Novas) Filipa Rodrigues / Pedro Souto / Artur Ferreira / Alexandre Varanda / Luís Gomes / Helena Gomes / João Zilhão

837 A pedra polida e afeiçoada do sítio do Neolítico médio da Moita do Ourives (Benavente, Portugal)

César Neves

857 Casal do Outeiro (Encarnação, Mafra): novos contributos para o conhecimento do povoamento do Neolítico final na Península de Lisboa.

Cátia Delicado / Carlos Maneira e Costa / Marta Miranda / Ana Catarina Sousa

873 Stresse infantil, morbilidade e mortalidade no sítio arqueológico do Neolítico Final/ Calcolítico ( $4^{\circ}$ e $3^{\circ}$ milénio a.C.) do Monte do Carrascal 2 (Ferreira do Alentejo, Beja) Liliana Matias de Carvalho / Sofia N. Wasterlain 
885 Come together: O Conjunto Megalítico das Motas (Monção, Viana do Castelo) e as expressões Campaniformes do Alto Minho Ana Catarina Basílio / Rui Ramos

899 Trabalhos arqueológicos no sítio Calcolítico da Pedreira do Poio Carla Magalhães / João Muralha / Mário Reis / António Batarda Fernandes

913 O sítio arqueológico de Castanheiro do Vento. Da arquitectura do sítio à arquitectura de um território João Muralha Cardoso

925 Estudo zooarqueológico das faunas do Calcolítico final de Vila Nova de São Pedro (Azambuja, Portugal): Campanhas de 2017 e 2018 Cleia Detry / Ana Catarina Francisco / Mariana Diniz / Andrea Martins / César Neves / José Morais Arnaud

943 As faunas depositadas no Museu Arqueológico do Carmo provenientes de Vila Nova de São Pedro (Azambuja): as campanhas de 1937 a 1967 Ana Catarina Francisco / Cleia Detry / César Neves / Andrea Martins / Mariana Diniz / José Morais Arnaud

959 Análise funcional de material lítico em sílex do castro de Vila Nova de S. Pedro (Azambuja, Portugal): uma primeira abordagem Rafael Lima

971 O recinto da Folha do Ouro 1 (Serpa) no contexto dos recintos de fossos calcolíticos alentejanos

António Carlos Valera / Tiago do Pereiro / Pedro Valério / António M. Monge Soares

\section{Proto-História}

987 Produção de sal marinho na Idade do Bronze do noroeste Português. Alguns dados para uma reflexão

Ana M. S. Bettencourt / Sara Luz / Nuno Oliveira / Pedro P. Simões / Maria Isabel C. Alves / Emílio Abad-Vidal

1001 A estátua-menir do Pedrão ou de São Bartolomeu do Mar (Esposende, noroeste de Portugal) no contexto arqueológico da fachada costeira de entre os rios Neiva e Cávado Ana M. S. Bettencourt / Manuel Santos-Estévez / Pedro Pimenta Simões / Luís Gonçalves

1015 O Castro do Muro (Vandoma/Baltar, Paredes) - notas para uma biografia de ocupação da Idade do Bronze à Idade Média

Maria Antónia D. Silva / Ana M. S. Bettencourt / António Manuel S. P. Silva / Natália Félix

1031 Do Bronze Final à Idade Média - continuidades e hiatos na ocupação de Povoados em Oliveira de Azeméis João Tiago Tavares / Adriaan de Man

1041 As faunas do final da Idade do Bronze no Sul de Portugal: leituras desde o Outeiro do Circo (Beja)

Nelson J. Almeida / Íris Dias / Cleia Detry / Eduardo Porfírio / Miguel Serra

1055 A Espada do Monte das Oliveiras (Serpa) - uma arma do Bronze Pleno do Sudoeste Rui M. G. Monge Soares / Pedro Valério / Mariana Nabais / António M. Monge Soares

1065 São Julião da Branca (Albergaria-a-Velha) - Investigação e valorização de um povoado do Bronze Final

António Manuel S. P. Silva / Paulo A. P. Lemos / Sara Almeida e Silva / Edite Martins de Sá

1083 Do castro de S. João ao Mosteiro de Santa Clara: notícia de uma intervenção arqueológica, em Vila do Conde Rui Pinheiro 
1095 O castro de Ovil (Espinho), um quarto de século de investigação - resultados e questões em aberto

Jorge Fernando Salvador / António Manuel S. P. Silva

1111 O Castro de Salreu (Estarreja), um povoado proto-histórico no litoral do Entre Douro e Vouga

Sara Almeida e Silva / António Manuel S. P. Silva / Paulo A. P. Lemos / Edite Martins de Sá

1127 Castro de Nossa Senhora das Necessidades (Sernancelhe): uma primeira análise artefactual Telma Susana O. Ribeiro

${ }_{1141}$ A cividade de Bagunte. O estado atual da investigação Pedro Brochado de Almeida

1153 Zoomorfos na cerâmica da Idade do Ferro no NW Peninsular: inventário, cronologias e significado Nuno Oliveira / Cristina Seoane

1163 Vasos gregos em Portugal: diferentes maneiras de contar a história do intercâmbio cultural na Idade do Ferro

Daniela Ferreira

1175 Os exotica da necrópole da Idade do Ferro do Olival do Senhor dos Mártires (Alcácer do Sal) no seu contexto regional

Francisco B. Gomes

\section{Antiguidade Clássica e Tardia}

1191 O uso de madeira como combustível no sítio da Quinta de Crestelos (Baixo Sabor): da Idade do Ferro à Romanização Filipe Vaz / João Tereso / Sérgio Simões Pereira / José Sastre / Javier Larrazabal Galarza / Susana Cosme / José António Pereira / Israel Espi

1207 Cultivos de Época Romana no Baixo Sabor: continuidade em tempos de mudança? João Pedro Tereso / Sérgio Simões Pereira / Filipe Santos / Luís Seabra / Filipe Vaz

1221 A casa romana na Hispânia: aplicação dos modelos itálicos nas províncias ibéricas Fernanda Magalhães / Diego Machado / Manuela Martins

1235 As pinturas murais romanas da Rua General Sousa Machado, n. ${ }^{5}$ 1, Chaves José Carvalho

1243 Trás do Castelo (Vale de Mir, Pegarinhos, Alijó) - Uma exploração agrícola romana do Douro

Tony Silvino / Pedro Pereira

1255 A sequência de ocupação no quadrante sudeste de Bracara Augusta: as transformações de uma unidade doméstica Lara Fernandes / Manuela Martins

1263 Os Mosaicos com decoração geométrica e geométrico-vegetalista dos sítios arqueológicos da área do Conuentus Bracaraugustanus. Novas abordagens quanto à conservação, restauro, decoração e datação Maria de Fátima Abraços / Licínia Wrench

1277 “Casa Romana” do Castro de São Domingos (Cristelos, Lousada): Escavação, Estudo e Musealização Paulo André de P. Lemos

1291 A arqueobotânica no Castro de Guifões (Matosinhos, Noroeste de Portugal): O primeiro estudo carpológico

Luís Seabra / Andreia Arezes / Catarina Magalhães / José Varela / João Pedro Tereso 
1305 Um Horreum Augustano na Foz do Douro (Monte do Castelo de Gaia, Vila Nova de Gaia) Rui Ramos

1311 Ponderais romanos na Lusitânia: padrões, formas, materiais e contextos de utilização Diego Barrios Rodríguez

1323 Um almofariz centro-itálico na foz do Mondego

Marco Penajoia

1335 Estruturas romanas de Carnide - Lisboa Luísa Batalha / Mário Monteiro / Guilherme Cardoso

1347 O contexto funerário do sector da "necrópole NO" da Rua das Portas de S. Antão (Lisboa): o espaço, os artefactos, os indivíduos e a sua interconectividade na interpretação do passado Sílvia Loja, José Carlos Quaresma, Nelson Cabaço, Marina Lourenço, Sílvia Casimiro, Rodrigo Banha da Silva, Francisca Alves-Cardoso

${ }_{1361}$ Povoamento em época Romana na Amadora - resultados de um projeto pluridisciplinar Gisela Encarnação / Vanessa Dias

1371 A Arquitectura Residencial em Mirobriga (Santiago do Cacém): contributo a partir de um estudo de caso Filipe Sousa / Catarina Felício

${ }_{1385}$ O fim do ciclo. Saneamento e gestão de resíduos nos edifícios termais de Mirobriga (Santiago do Cacém)

Catarina Felício / Filipe Sousa

1399 Balsa, Topografia e Urbanismo de uma Cidade Portuária Vítor Silva Dias / João Pedro Bernardes / Celso Candeias / Cristina Tété Garcia

1413 No Largo das Mouras Velhas em Faro (2017): novas evidências da necrópole norte de Ossonoba e da sua ocupação medieval Ricardo Costeira da Silva / Paulo Botelho / Fernando Santos / Liliana Nunes

1429 Instrumentos de pesca recuperados numa fábrica de salga em Ossonoba (Faro) Inês Rasteiro / Ricardo Costeira da Silva / Paulo Botelho

1439 A Necrópole Romana do Eirô, Duas Igrejas (Penafiel): intervenção arqueológica de 2016 Laura Sousa / Teresa Soeiro

1457 Ritual, descarte ou afetividade? A presença de Canis lupus familiaris na Necrópole Noroeste de Olisipo (Lisboa)

Beatriz Calapez Santos / Sofia Simões Pereira / Rodrigo Banha da Silva / Sílvia Casimiro / Cleia Detry / Francisca Alves Cardoso

1467 Dinâmicas económicas em Bracara na Antiguidade Tardia Diego Machado / Manuela Martins / Fernanda Magalhães / Natália Botica

1479 Cerâmicas e Vidros da Antiguidade Tardia do Edifício sob a Igreja do Bom Jesus (Vila Nova de Gaia) Joaquim Filipe Ramos

1493 Novos contributos para a topografia histórica de Mértola no período romano e na Antiguidade Tardia Virgílio Lopes

\section{8. Época Medieval}

1511 Cerâmicas islâmicas no Garb setentrional "português": algumas evidências e incógnitas Constança dos Santos / Helena Catarino / Susana Gómez / Maria José Gonçalves / Isabel Inácio / Gonçalo Lopes / Jacinta Bugalhão / Sandra Cavaco / Jaquelina Covaneiro / Isabel Cristina Fernandes / Ana Sofia Gomes 
1525 Contributo para o conhecimento da cosmética islâmica, em Silves, durante a Idade Média Rosa Varela Gomes

1537 Yábura e o seu território - uma análise histórico-arqueológica de Évora entre os séculos VIII-XII José Rui Santos

1547 A encosta sul do Castelo de Palmela - resultados preliminares da escavação arqueológica Luís Filipe Pereira / Michelle Teixeira Santos

1559 A igreja de São Lourenço (Mouraria, Lisboa): um conjunto de silos e de cerâmica medieval islâmica

Andreia Filipa Moreira Rodrigues

1571 O registo material de movimentações populacionais no Médio Tejo, durante os séculos XII-XIII. Dois casos de "sunken featured buildings", nos concelhos de Cartaxo e Torres Novas Marco Liberato / Helena Santos / Nuno Santos

1585 O nordeste transmontano nos alvores da Idade média. Notas para reflexão Ana Maria da Costa Oliveira

1601 Sepulturas escavadas na rocha do Norte de Portugal e do Vale do Douro: primeiros resultados do Projecto SER-NPVD

Mário Jorge Barroca / César Guedes / Andreia Arezes / Ana Maria Oliveira

1619 "Portucalem Castrum Novum" entre o Mediterrâneo e o Atlântico: o estudo dos materiais cerâmicos alto-medievais do arqueossítio da rua de D. Hugo, nํ. 5 (Porto) João Luís Veloso

1627 A Alta Idade Média na fronteira de Lafões: notas preliminares sobre a Arqueologia no Concelho de Vouzela

Manuel Luís Real / Catarina Tente

1641 Um conjunto cerâmico medieval fora de portas: um breve testemunho aveirense Susana Temudo

${ }_{1651}$ Os Lóios do Porto: uma perspetiva integrada no panorama funerário da Baixa Idade Média à Época Moderna em meios urbanos em Portugal

Ana Lema Seabra

1659 O Caminho Português Interior de Santiago como eixo viário na Idade Média Pedro Azevedo

1665 Morfologia Urbana: Um exercício em torno do Castelo de Ourém André Donas-Botto / Jaqueline Pereira

1677 Intervenção arqueológica na Rua Marquês de Pombal/Largo do Espírito Santo (Bucelas, Loures)

Florbela Estêvão / Nathalie Antunes-Ferreira / Dário Ramos Neves / Inês Lisboa

1691 O Cemitério Medieval do Poço do Borratém e a espacialidade funerária na cidade de Lisboa Inês Belém / Vanessa Filipe / Vasco Noronha Vieira / Sónia Ferro / Rodrigo Banha da Silva

1705 Um Espaço Funerário Conventual do séc. XV em Lisboa: o caso do Convento de São Domingos da Cidade Sérgio Pedroso / Sílvia Casimiro / Rodrigo Banha da Silva / Francisca Alves Cardoso

\section{9. Época Moderna e Contemporânea}

1721 Arqueologia Moderna em Portugal: algumas reflexões críticas em torno da quantificação de conjuntos cerâmicos e suas inferências históricas e antropológicas Rodrigo Banha da Silva / André Bargão / Sara da Cruz Ferreira

1733 Faianças de dois contextos entre os finais do século XVI e XVIII do Palácio dos Condes de Penafiel, Lisboa

Martim Lopes / Tomás Mesquita 
1747 Um perfil de consumo do século XVIII na foz do Tejo: O caso do Mercado da Ribeira, Lisboa Sara da Cruz Ferreira / Rodrigo Banha da Silva / André Bargão

1761 Os Cachimbos dos Séculos XVII e XVIII do Palácio Mesquitela e Convento dos Inglesinhos (Lisboa)

Inês Simão / Marina Pinto / João Pimenta / Sara da Cruz Ferreira / André Bargão / Rodrigo Banha da Silva

1775 "Tomar os fumos da erua que chamão em Portugal erua sancta». Estudo de Cachimbos provenientes da Rua do Terreiro do Trigo, Lisboa

Miguel Martins de Sousa / José Pedro Henriques / Vanessa Galiza Filipe

1787 Cachimbos de Barro Caulínitico da Sé da Cidade Velha (República de Cabo Verde)

Rodrigo Banha da Silva / João Pimenta / Clementino Amaro

1801 Algumas considerações sobre espólio não cerâmico recuperado no Largo de Jesus (Lisboa) Carlos Boavida

1815 Adereços de vidro, dos séculos XVI-XVIII, procedentes do antigo Convento de Santana de Lisboa (anéis, braceletes e contas)

Joana Gonçalves / Rosa Varela Gomes / Mário Varela Gomes

1837 Da ostentação, luxo e poder à simplicidade do uso quotidiano: arqueologia e simbologia de joias e adornos da Idade Moderna Portuguesa Jéssica Iglésias

1849 Os amuletos em Portugal - dos objetos às superstições: o coral vermelho Alexandra Vieira

1865 Cerâmicas de Vila Franca de Xira nos séculos XV e XVI Eva Pires

1879 «Não passa por teu o que me pertence». Marcas de individualização associadas a faianças do Convento de Nossa Senhora de Aracoeli, Alcácer do Sal Catarina Parreira / Íris Fragoso / Miguel Martins de Sousa

1891 Cerâmica de Leiria: alguns focos de produção

Jaqueline Pereira / André Donas-Botto

1901 Os Fornos na Rua da Biquinha, em Óbidos Hugo Silva / Filipe Oliveira

1909 A casa de Pêro Fernandes, contador dos contos de D. Manuel I: o sítio arqueológico da Silha do Alferes, Seixal (século XVI) Mariana Nunes Ferreira

1921 O Alto da Vigia (Sintra) e a vigilância e defesa da costa Alexandre Gonçalves / Sandra Santos

1937 O contexto da torre sineira da Igreja de Santa Maria de Loures Paulo Calaveira / Martim Lopes

1949 A Necrópole do Hospital Militar do Castelo de São Jorge e as práticas funerárias na Lisboa de Época Moderna Susana Henriques / Liliana Matias de Carvalho / Ana Amarante / Sofia N. Wasterlain

1963 SAND - Sarilhos Grandes Entre dois Mundos: o adro da Igreja e a Paleobiologia dos ossos humanos recuperados

Paula Alves Pereira / Roger Lee Jesus / Bruno M. Magalhães

1975 Expansão urbana da vila de Cascais no século XVII e XVIII: a intervenção arqueológica na Rua da Vitória no 15 a 17

Tiago Pereira / Vanessa Filipe

1987 Novos dados para o conhecimento do Urbanismo de Faro em época Moderna Ana Rosa 
1995 Um exemplo de Arqueologia Urbana em Alcoutim: o Antigo Edifício dos CTT Marco Fernandes / Marta Dias / Alexandra Gradim / Virgílio Lopes / Susana Gómez Martínez

2007 Palácio dos Ferrazes (Rua das Flores/Rua da Vitória, Porto): a cocheira de Domingos Oliveira Maia

Francisco Raimundo

2021 As muitas vidas de um edifício urbano: História, Arqueologia e Antropologia no antigo Recreatório Paroquial de Penafiel Helena Bernardo / Jorge Sampaio / Marta Borges

2035 O convento de Nossa Senhora da Esperança de Ponta Delgada: o contributo da arqueologia para o conhecimento de um monumento identitário João Gonçalves Araújo / N’Zinga Oliveira

2047 Arqueologia na ilha do Corvo... em busca da capela de Nossa Senhora do Rosário Tânia Manuel Casimiro / José Luís Neto / Luís Borges / Pedro Parreira

2059 Perdidos à vista da Costa. Trabalhos arqueológicos subaquáticos na Barra do Tejo Jorge Freire / José Bettencourt / Augusto Salgado

2071 Arqueologia marítima em Cabo Verde: enquadramento e primeiros resultados do projecto CONCHA

José Bettencourt / Adilson Dias / Carlos Lima / Christelle Chouzenoux / Cristóvão Fonseca / Dúnia Pereira / Gonçalo Lopes / Inês Coelho / Jaylson Monteiro / José Lima / Maria Eugénia Alves / Patrícia Carvalho / Tiago Silva

2085 Trabalhos arqueológicos na Cidade Velha (Ribeira Grande de Santiago, Cabo Verde): reflexões sobre um projecto de investigação e divulgação patrimonial André Teixeira / Jaylson Monteiro / Mariana Mateus / Nireide Tavares / Cristovão Fonseca / Gonçalo C. Lopes / Joana Bento Torres / Dúnia Pereira / André Bargão / Aurélie Mayer / Bruno Zélie / Carlos Lima / Christelle Chouzenoux / Inês Henriques / Inês Pinto Coelho / José Lima / Patrícia Carvalho / Tiago Silva

2103 A antiga fortificação de Quelba / Khor Kalba (E.A.U.). Resultados de quatro campanhas de escavações, problemáticas e perspectivas futuras Rui Carita / Rosa Varela Gomes / Mário Varela Gomes / Kamyar Kamyad

2123 Colónias para homens novos: arqueologia da colonização agrária fascista no noroeste ibérico Xurxo Ayán Vila / José Mạ . Señorán Martín 


\title{
ARQUEOLOGIA MODERNA EM PORTUGAL: ALGUMAS REFLEXÕES CRÍTICAS EM TORNO DA QUANTIFICAÇÃO DE CONJUNTOS CERÂMICOS E SUAS INFERÊNCIAS HISTÓRICAS E ANTROPOLÓGICAS
}

\author{
Rodrigo Banha da Silva ${ }^{1}$, André Bargão ${ }^{2}$, Sara da Cruz Ferreira ${ }^{3}$
}

\begin{abstract}
RESUMO
A Arqueologia Moderna vem notoriamente ganhando espaço na Arqueologia Portuguesa, não só no que se refere ao número de intervenções arqueológicas, como no que respeita ao número de publicações de sítios, contextos e cultura material. Ressalta, todavia, que este crescendo de conhecimento não aparece acompanhado de uma maior sofisticação metodológica, debruçando-se os autores sobre um dos aspectos deste panorama: a quantificação de conjuntos artefactuais, em particular cerâmicas, e a relação desta com o esclarecimento dos perfis funcionais dos contextos arqueológicos respectivos; deverá notar-se que um e outro elemento são condições de base essenciais para a produção das inferências de carácter histórico e antropológico. Palavras-chave: Arqueologia Moderna, Metodologia Arqueológica, Teoria em Arqueologia.
\end{abstract}

\begin{abstract}
Early Modern Archaeology is becoming a nodal área of study in Portuguese Archaeology, due to the increasing numbers of excavations, as in terms of publication of sites, contexts and material culture. Nevertheless, this progress doesn't display a refined preoccupation on methodology and theoretical frameworks. The authors address this issue focusing its interest on artefact assemblages and categories quantification and its narrow relation to context functional profile, noteworthy two of the fundamental basis allowing historical and anthropological inferences.

Keywords: Historical Archaeology, Post-Medieval Archaeology, Archaeological Quantification, Theoretical Archaeology.
\end{abstract}

\section{INTRODUÇÃO}

A Arqueologia Moderna em Portugal estabeleceu desde cedo benéficas pontes epistemológicas com outras disciplinas, em cujos domínios se enraíza o seu nascimento. A História desde cedo assomou como espaço de contacto privilegiado, proporcionando fontes escritas, cartográficas e iconográficas para a interpretação dos sítios, contextos, artefactos e suas cronologias. Todavia, e não poucas vezes ao longo da curta evolução da Arqueologia da Época Moderna em Portugal, o conhecimento obtido por esta área disciplinar assumiu o papel secundário de mera ilustração das leituras de outro modo produzidas previamente pela História (Gomes, 2012). Por seu turno, a História da Arte e, em paralelo com esta, quer o Coleccionismo, quer o Antiquarismo (com A grande), constituem outro ponto de forte contacto disciplinar, proporcionando à área valiosos capitais de conhecimento acumulados num tempo longo

\footnotetext{
1. Departamento de História NOVA FCSH. CHAM - Centro de Humanidades NOVA FCSH.rbds@fcsh.unl.pt

2. Bolseiro de Doutoramento FCT SFRH/BD/133757/2017. CHAM - NOVA FCSH, andrebargao@gmail.com

3. Bolseira de Doutoramento FCT SFRH/BD/137142/2018. CHAM - NOVA FCSH, sara.isabel91@hotmail.com
} 
(Gomes, 2012, pp. 53-59; Barker \& Majewski, 2014). Deverá notar-se, todavia, que nem a História nem a História da Arte, como as restantes disciplinas mencionadas, se fundam nos mesmos pressupostos da Arqueologia, encerram os mesmos objectivos ou fazem uso das mesmas metodologias de construção de conhecimento, pelo que os vários discursos disciplinares deveriam ser obviamente distintos. Por esta razão, também, a transferência simples dos conhecimentos obtidos pelas outras disciplinas para o domínio da Arqueologia encerra problemáticas sobre as quais importaria reflectir e discutir.

Ora, e no âmbito assim definido como pano de fundo, faz-se uso no presente texto das cerâmicas de Época Moderna e da sua quantificação como tema de abordagem privilegiado, considerando-se que a presença das elaborações oleiras nos contextos arqueológicos com aquelas cronologias encerram valor significante para a construção das leituras sociais e comportamentais do passado. As escolhas metodológicas de quantificação, portanto, são determinantes para a qualidade das inferências que compõem o discurso arqueológico, e constituem uma parte relevante do quadro teórico disciplinar: "The critical scrutiny of patterns of archaeological reasoning immediately exposes the basic importance of archaeological logic within archaeological philosophy and theory. Archaeological logic should outline for us the theory of correct reasoning within our discipline, without making any unwarranted assumptions that the principles of logic and explanation are simple universals which may be transferred from one discipline and level to another... It raises the problems of the nature of the logical conclusions between archaeological conclusions and the grounds for these conclusions" (Clarke, 1973, p. 15).

\section{QUANTIFICAÇÃO E PENSAMENTO ARQUEOLÓGICO: UMA CURTA REFERÊNCIA TEMPORAL}

O movimento anglo-saxónico da New Archaeology (mais tarde designado por Processualismo) pugnou, desde as suas etapas iniciais, por um refinamento metodológico, com a quantificação a encerrar um papel de primeiro plano, sendo aquele considerado fundamento indispensável para a produção de um discurso mais racionalizado, bem patente e expresso em textos "fundacionais", com especial no- toriedade para os de David Clarke (1986) e Lewis Binford (1968 - este último precedido na Antropologia norte-americana por Albert Spaulding, 1953). Defendia-se, então, uma ruptura com os paradigmas de pensamento precedentes, histórico-culturalistas, onde a relação dos artefactos com os modos de vida do passado se perdia assim que estes elementos eram incluídos no registo arqueológico e onde, portanto, a tarefa do arqueólogo se centrava na catalogação, descrição e criação de padrões classificatórios, sobretudo cronológicos (Trigger, 1989, p. 148). A reacção atingiu a mais vincada notoriedade décadas de 1980 e inícios da de 1990, com saliência para o "contextualista/simbolista" Ian Hodder (1982), mas também com a necessária referência aos seus ex-alunos cambrigianos como Michael Shanks e Christopher Tilley (1992). A inflamada controvérsia teórica anglo-saxónica ocorrida dos dois lados do Atlântico, envolveu as mais diversas "facções" (Hodder \& Hutton, 2003), e resultaria depois no pós-processualismo. Independentemente da tendência ou sensibilidade teórico-filosófica em que depois se posicionaram neste quadro, qualquer das tendências deixou incólume a validade da quantificação como uma das bases metodológicas disciplinares, transversal às várias "arqueologias" e ferramenta mental da disciplina (Shennan, 1997).

Pela via que acabámos de expor, de uma forma exageradamente sintética para a riqueza de problemáticas que o tema encerra, as arqueologias norte-americana e britânica rapidamente incorporaram na sua praxis a quantificação e a estatística ao nível mais básico do trabalho, o que incluiu o tratamento da cerâmica nos relatórios de escavação.

Rapidamente, a Europa Continental acompanhou a tendência, embora não de uma forma tão homogénea como a britânica. Um mapeamento, se executado, revelaria a expressão da generalização progressiva das metodologias ao nível básico da praxis por manchas geográficas, mas em contrapartida assinalaria numerosos vazios (entre um leque amplo de títulos que abordam o tema destacaríamos Madsen, 1988; Desbat, 1990; Arcelin \& Tuffreau-Libre, 1998; Husi, 2001).

De outro modo, a universalidade ontológica e a transversalidade das metodologias (Orton, 1980; Fletcher, 1991, mas sobretudo, Orton, Tyers \& Vince, 1993; Arcelin \& Tuffreau-Libre, 1998, Husi, 2001) não foi de igual modo acolhida nas várias "arqueolo- 
gias históricas" continentais (aqui entendidas de um ponto de vista cronológico alargado). A uma generalizada e forte aceitação e valorização no âmbito dos estudos em Arqueologia Clássica, contrapôs-se um incompreensível menor sucesso no âmbito das arqueologias Medieval e Moderna europeias. Será por estas estarem, por tradição, muito mais conectadas à História da Arte e à valorização do artefacto como "objecto individual” significante? E assim sendo, será esta via válida para as construções das leituras das sociedades pretéritas como alternativa à abordagem contextualizada do conjunto? A resposta, que é necessariamente negativa à segunda pergunta, implica uma outra forçosamente negativa à questão que a precede, pelo menos se não nos revemos de um ponto de vista conceptual nos paradigmas histórico-culturalistas da arqueologia, e se reconhecemos à disciplina a capacidade de proporcionar com base na cultura material leituras bem mais ricas e diversificadas sobre o passado (sociais, culturais, antropológicas...).

A respeito do que se vem expondo, é deveras evocativo que à chamada à primeira reunião francesa em torno da quantificação das cerâmicas, realizada em Glux-en-Glenne no ano de 1997, só num caso a resposta veio de fora da Arqueologia Romana (conf. Arcelin \& Tuffreau-Libre, 1998). Este panorama, que é também o português, vem sendo assinalado em diversa produção científica europeia de reflexão a propósito dos estudos sobre cerâmica abrangendo a do período moderno, cabendo citarem-se aqui exemplos como os de Philippe Husi (2001) para Tours, ou Maxime Poulain (2013), este último em referência circunstanciada à arqueologia post-medieval Belga e dos Países Baixos, qualquer dos dois indicando exemplos de múltiplas outras geografias elencados na bibliografia respectiva.

As problemáticas que envolvem o uso da quantificação da cerâmica arqueológica no âmbito dos estudos de Arqueologia Moderna são de natureza teórica porque esta lhes serve de pano de fundo: não correspondem, portanto, a uma qualquer manifestação de militância engagée, muito menos a uma moda ou estilo. Melhor seria, passado quase meio século das primeiras publicações que definiram metodologicamente a questão e os contornos do seu significado! (com destaque para o trabalho perseverante e fundamental de Clive Orton, 1975, 1979, 1980, 1982, 1989, 1993; Orton, Tyers \& Vince, 1993; Orton \& Hughes, 2013).
Não se pretende tomar aqui como objecto de discussão quais das distintas abordagens assumem maior ou menor fidedignidade, assunto amplamente discutido a nível internacional (ver por ex.: Husi, 2001). $\mathrm{Ou}$, sequer, se todos fizeram uso das ferramentas colocadas ao nosso dispor pela quantificação: claro que nem todos delas fizeram uso, não encerrando esta opção de per si um problema de maior. Todavia, não se pode deixar de fazer notar que permanecer ignorante acerca das ferramentas e pressupostos da quantificação é, não só infeliz, como desnecessário, porque, pelo menos, deter este tipo básico de conhecimento é condição necessária para entender e avaliar o trabalho dos outros investigadores que delas fazem uso...

\section{UMA MUITO CURTA, GENÉRICA E INCOMPLETA, MAS SIGNIFICANTE, REFERÊNCIA AO CASO PORTUGUÊS...}

De forma feliz se dá a coincidência de a reunião científica de arqueólogos que deu origem ao texto presente se realizar na cidade do Porto. Na realidade, terá que se encarar ao nível nacional como dotada de carácter inovador, e quiçá arrojado, a abordagem produzida para a Época Moderna pela equipa que trabalhou a intervenção urbana na Casa do Infante (Porto), que escavou, tratou e compulsou o vasto conjunto de meio milhão de fragmentos cerâmicos oriundos dos contextos datados de entre os séculos XVI e XVIII, aplicando em 1991 as mais actualizadas metodologias à época (Real et al., 1995), e logo incorporando as de quantificação (recorde-se que a obra de Orton, Tyers \& Vince fora pela primeira vez publicada em 1993). Mais importante, e depois de uma primeira publicação preliminar da longa sequência do ponto arqueológico da cidade do Porto (Real et al., 1995), de forma assaz rápida foram exaustivamente disponibilizados os resultados em 1995, por ocasião do II "colóquio de Tondela" (Castro, Dórdio \& Teixeira, 1998), prosseguindo pelos anos seguintes (conf. bibliografia cotejada em Real et al., 2015). Paulo Dórdio Gomes, inclusive, publicaria logo após um valioso artigo, circunstanciado, explicitando e clarificando com detalhe as opções metodológicas adoptadas pela equipa em relação à contabilização da cerâmica (Dórdio, 1997/1998).

Seria expectável, portanto, que o trabalho dos vários elementos da equipa da Casa do Infante representasse o bem-sucedido advento de uma praxis envol- 
vendo metodologias de quantificação de cerâmica na Arqueologia Moderna portuguesa, e que estas se tivessem rapidamente expandido à escala nacional. Infelizmente assim não aconteceu, e até data recente os protocolos quantitativos ficaram somente confinados a um grupo de investigadores nortenhos que se foi muito paulatinamente alargando, ao mesmo tempo que aquelas "ferramentas" se disseminavam e vulgarizavam em Portugal no âmbito das "outras arqueologias” (sobretudo pré, proto-histórica e romana). O que terá falhado então? Na perspectiva dos signatários, por um lado a forma de transmissão do saber e das instituições a quem este comete primordialmente. Por outro, a maneira dominante de fazer arqueologia em Portugal, por contrato, e à forma como o Estado desde cedo (década de 199o) desvalorizou todo o trabalho arqueológico pós-escavação. O panorama actual português actual é, todavia, o de transformação e viragem, mesmo que notoriamente insuficiente por força da massa ciclópica de dados acumulados nos últimos 30 anos. Tendo por força que se correr o risco de ser injusto ao nomear de maneira particularizada investigadores, para além de um conjunto alargado de arqueólogos nortenhos (Paulo Dórdio Gomes, Ricardo Teixeira, António Manuel Silva, Rosário Melo, Maria Isabel Pinto Osório, Miguel Rodrigues,...), cabe aqui destacarem-se em datas mais recentes Ricardo Costeira da Silva (ex.: 2013, 2016a, 2016b), para o caso coimbrão, ou o grupo de investigadores de Lisboa com conexões à Faculdade de Ciências Sociais e Humanas da Universidade Nova de Lisboa, independentemente do seu enquadramento actual, e no qual se inscrevem os autores. Trata-se, por conseguinte, de um tempo novo, que prenuncia abordagens bastante mais ricas e complexas do que as clássicas inferências que directamente se retiram do imprescindível trabalho classificatório inicial, que mais não permite do que a aferição dos elementos de origem e cronológico (do objecto e/ou do contexto respectivo), deste modo autorizando inferências genéricas e não poucas vezes vagas de cariz económico (seja a conexão entre distintos pontos geográficos, seja a noções imprecisas e difusas -quando não tantas vezes abusivas- sobre as dinâmicas) e de índole socio-cultural (evoluções do uso, definição de status social ou poder aquisitivo).

\section{ALGUMAS (POUCAS) PROBLEMÁTICAS SELECCIONADAS EM QUANTIFICAÇÃO DE CERÂMICAS DA ÉPOCA MODERNA EM PORTUGAL}

É um conceito basilar da disciplina que um objecto arqueológico encerra em si próprio diferentes tempos, compreendidos entre o momento da sua manufactura (que pressupõe a ideia prévia do objecto) até ao momento da sua recolha, envolvendo no entretanto um conjunto mais ou menos complexo de processos (Lamotta \& Schiffer, 2005, pp. 123-125). Como consequência, o primeiro passo da análise cerâmica relaciona-se com a tentativa de compreensão e leitura desses mesmos processos, condição para a construção do conhecimento subsequente sobre o conjunto cerâmico em estudo, o que é o mesmo que dizer que o pressuposto de partida é o esclarecimento da definição dos contornos funcionais dos contextos, expressão feliz avançada, noutro âmbito totalmente diferente, por Josep Antón Remolá Vallverdú (200o, p. 15 e segs.).

\subsection{O contexto como pressuposto: uma nota}

Ao contrário de outras "arqueologias", a Arqueologia Moderna (como a Medieval, sobretudo na Baixa Idade Média) encerra uma enorme virtualidade, que é a de dispor de uma vasta massa de informação histórica (textual, iconográfica, cartográfica, ...) que esclarece muitas vezes não só acerca da cronologia, como sobre a natureza socio-económica e cultural dos prováveis agentes da formação dos contextos, proporcionando ainda elementos sobre uma parte relevante das acções praticadas à época nos momentos de uso e nos de pós-desfuncionalização dos objectos (reciclagem, transporte, refuncionalização, ...).

A análise quantitativa dos conjuntos cerâmicos modernos beneficia, por consequência, desses dados externos altamente qualificados. O facto constitui uma enorme virtualidade disciplinar, a qual deveria fazer-lhe valer um local de destaque metodológico no âmbito geral da arqueologia, considerando o potencial informativo dos modelos empíricos que deveria produzir para a interpretação de contextos e "cultura material" também "histórica", mas de outras épocas.

Em sentido reverso, a análise de determinados parâmetros da contabilização cerâmica (com por exemplo o grau de fragmentação, entre outros) deveria verter também para a leitura dos contextos e do res- 
pectivo perfil funcional. Entre muitíssimos exemplos que se poderiam cotejar, veja-se o contraste extremo entre um contexto de uma lareira de uma cozinha doméstica, capsulado no tempo pelo terramoto de Lisboa de 1755, composto por quatro panelas e respectivos testos (Diogo \& Trindade, 1995; que é o mesmo que dizer $8 \mathrm{NMI}$ ), com os 12975 fragmentos $=7726$ NMI cerâmicos estudados dos contextos de um aterro formado após o cataclismo e antes de 1780 no quadro das intervenções ribeirinhas de ampliação do Forte de São Paulo (Ferreira, 2015); ou, na mesma cidade, e a propósito do perfil socio-económico, os ratios de fragmentos de cachimbo por $\mathrm{m} 2$ de vários locais que, a despeito de obtidos de forma assumidamente grosseira e impressionista, espelham o peso do contexto militar ou de ambientes britânicos neste tipo de ocorrências (vide Simão et al., no prelo, no presente volume).

\subsection{Para uma biografia dos objectos}

Retomando a ideia inicial do apartado, a dimensão biográfica dos artefactos e dos processos que medeiam entre a sua concepção e o descarte e desfuncionalização foi já abordada por numerosa e diversa literatura que aflorou circunstancialmente o tempo de vida a uso dos objectos com base na coerência contextual, na discrepância cronológica, envolvendo os traços de manuseamento ou, inclusive, a própria "esperança de vida" de diferentes categorias cerâmicas. Neste sentido, e viajando uma vez mais para fora do âmbito cronológico do presente trabalho, talvez mereça destaque o enfrentamento circunstanciado e claro da matéria desenvolvido por J. Theodor Peña, precedido muito tempo antes de forma menos sofisticada por Clive Orton $(1975,1979)$, que ensaiou a definição da "chaine operatoire" e os tempos de esperança de vida médios para várias categorias cerâmicas romanas com base em informação itálica (Peña, 2007, p. 58 e segs.).

Neste sentido, os dados obtidos mais recentemente para contextos modernos lisboetas são reveladores: nos contextos a que já aludimos do Mercado da Ribeira, quando as outras produções oleiras exógenas datadas com anterioridade aos meados do séc. XVII são escassas ( $36 \mathrm{NMI}=0,47 \%$ do total NMI), na porcelana as elaborações orientais (191 NMI $=1,32 \%$ do total NMI), do séc. XVI são 23,53 \% do total de porcelana, do último quartel do séc. XVI-primeira metade do séc. XVII são 17,64 \%, i.e., 41,17\% da porcelana do local tem 100 anos ou mais antes do seu descarte (Ferreira, 2015), implicando especiais cuidados no seu manuseamento que lhes prolongaram longamente a vida; no contexto de um poço do Hospital Real de Todos-Os-Santos, em curso de estudo por um dos autores (AB), apesar de desactivado após o grande incêndio de 1750, nele pontuava um exemplar único de faiança de Savona (Itália) anterior a 1640, e a faiança portuguesa, de uso corrente na cidade que era um dos seus principais centros produtores (senão o principal), revelou que $86,05 \%$ dos 155 NMI mostravam gramáticas decorativas que, de acordo com a mais recente investigação sobre o tema (Casimiro, 2010, 2013), deixaram de ser produzidas em 1700 ou antes; noutro contexto, amplo de 939 NMI cerâmicos, formado provavelmente no âmbito de uma obra no interior de um prédio nos primeiros anos do séc. XVIII (antes interpretado como o descarte de uma cozinha de 1755 - Trindade \& Diogo, 2003, p. 288), para além dos 640 indivíduos de "cerâmica fosca de barro vermelho" (panelas, sertãs, jarros, bilhas,...), e deixando de parte nova ocorrência solitária de faiança lígure da $1^{\underline{a}}$ metade do séc. XVII, na faiança portuguesa somente $13,19 \%$ (dos $144 \mathrm{NMI}$ ) equivalem a gramáticas decorativas a que se atribuem um início de produção ulterior a 1680 (Ferreira et al., no prelo, figs. 8 e 11).

\subsection{Curta referência em torno das escolhas meto- dológicas de contagem...}

As propostas compostas de forma mais estruturada e com intenção de difusão por Clive Orton, Paul Tyers e Alan Vince (1993), depois replicadas em Mont Beuvray (Arcelin \& Tuffreau-Livre, 1998) com porventura mais expressivo acolhimento continental, consideraram diferentes possibilidades estatísticas de enfrentamento da contabilização da cerâmica: o número máximo de indivíduos (MNI), equivalente à contagem de fragmentos (descartando a duplicação da contagem dos fragmentos com colagem entre si); o cálculo do peso, depois refinado em função de várias operações requeridas pelas diferenças entre as várias categorias e tipos cerâmicos; a estimativa do número mínimo de indivíduos (NMI), obtida pelo cruzamento da contabilização de todas as diferentes porções de peças (bordos, fundos, asas, pegas, carenas, paredes- conf. por exemplo Husi, 2001, p. 5), e que requer a execução prévia dos "puzzlings"; por fim o "EVE" (equivalent vessel estimate), obtido a partir de uma tabela de diâmetros onde conste a representação das percentagens da porção do ele- 
mento de bordo ou fundo presente, depois somada e transformada ou em número de indivíduos EVE, ou em percentagem.

Desde a década de 1990 que se encetou a discussão em torno de qual a escolha metodológica que melhor servia os propósitos da investigação, servindo a discussão para comprovar as virtualidades dos cálculos do peso em determinadas circunstâncias, nomeadamente na comparação entre distintas produções (Husi, 2001, p. 7); de aceitação mais generalizada aceite foi o cômputo dos NMI (Arcelin \& Tuffreau-Libre, 1998, Husi, 2001; Poulain, 2013); a adequação da aplicabilidade do EVE foi identificada para certos casos específicos, casuisticamente importantes para as inferências de natureza cronológica, visto que os EVE recorrentemente apresentam resultados em harmonia com os obtidos para o NMI por força dos procedimentos classificatórios antes adoptados para o estimar, parecendo jogar aqui um papel decisivo o maior grau de fragmentação das cerâmicas (Husi, 2001, p. 6).

No caso presente, efectuámos um ensaio-teste aos resultados obtidos para as cerâmicas contidas na colmatação de um poço medieval localizado junto às traseiras do Hospital Real de Todos-Os-Santos (Lisboa), desactivando-o nas primeiras décadas do séc. XVII, sendo evidente a harmonia dos gráficos obtidos em termos de EVE e NMI (Figura 1).

A conclusão a retirar é a de que, de facto, as discrepâncias na comparação entre NMI e EVE aumentam na mesma medida da subida do grau de fragmentação, como já tinha sido observado por Philippe Husi (2001, p. 6), mas necessariamente esta verificação só adquirirá validade mediante a sua aplicação noutros quadros geográficos portugueses, e, considerando o caso específico dos contextos urbanos, multiplicando a análise em diferentes molduras (sociais, económicas, culturais, ...), considerando a natureza necessariamente heterotópica das cidades.

\subsection{A quantificação como datação diacrónica}

Embora a Arqueologia Moderna beneficie fortemente dos contributos externos da documentação histórica para a definição das cronologias dos seus contextos, para uma parte importante dos casos das unidades estratigráficas exumadas, como para sequências estratigráficas complexas, o estudo global da cerâmica abre possibilidades de definição de frequências expressas em tendências de "associações", que compõem um útil instrumento na definição dos contornos cronológicos para outros contextos. Para tomar um caso português, impõe-se o "retorno" à Casa do Infante (Porto), dado que essa foi, justamente, a mais evidente virtualidade do trabalho desenvolvido para a Arqueologia Moderna Portuguesa ali executado na primeira metade da década de 1990 (Castro, Dórdio \& Teixeira, 1998 e todos os trabalhos ulteriores elencados em Real et al. 2015). Aqui, a contabilização usando as metodologias actualizadas de contagem descartou os mais ponderosos factores aleatórios, casos das assimetrias de representatividade induzidas pelos diferentes padrões de fragmentação, ou a selectividade classificatória que, um e outro, caracterizam as contagens tradicionais por número de fragmentos (MNI), definindo para o lugar os indicadores de tendências evolutivas do consumo cerâmico.

Obtêm-se também, e deste modo, as ferramentas de produção de dados que possibilitam tratamentos estatísticos ulteriores. Destes, elegemos somente um, por manifestamente acessível de um ponto de vista matemático: as curvas de tendência diacrónica. Estas podem ser globais, temáticas, tópicas ou contextuais, de qualquer das formas destinadas ao enfrentamento de conjuntos com uma boa qualidade de informação, quer ao nível da sua mínima representatividade quantitativa, quer da natureza dos conhecimentos crono-tipológicos das categorias cerâmicas prévios. As curvas de tendência diacrónica partem de um princípio quase elementar: com base no NMI, se uma cerâmica encerra balizas cronológicas situadas ao longo de 5 décadas, e se a análise for, por exemplo, quinquenal, isso significa no abstracto a probabilidade daquele indivíduo se distribuir equitativamente $\mathrm{o}$ individuo pelos 10 intervalos quinquenais que compõem as 5 décadas, i.e., procedendo-se à distribuição do valor 1 por todos os intervalos de forma equitativa, ou seja, representando o valor de o,1 distribuído por cada um dos intervalos. Repetindo-se o procedimento de forma cumulativa com os restantes indivíduos, obtém-se então uma curva probabilística de indicadores cronológicos.

O método, desenvolvido a outro propósito (Silva, 2005), mas afinal já antes ensaiado por Elisabeth Fentress e Philip Perkins (1988), fornece tão somente valores indiciadores, experimentados também com sucesso no âmbito da Arqueologia Moderna (exs.: Almeida, 2013; Ferreira, 2015; Ferreira \& Bargão, 2016; Ferreira et al., 2017; Ferreira et al., no prelo). 
4.5. "Size matters": metrologia...

Não cabe aqui entrar em profundidade com a relevância que teve a "arquitectura mental matemática" dos indivíduos do passado, em particular na Época Moderna, que para mais assiste ao desenvolvimento do empirismo e do racionalismo, e que tem vincada expressão científica (matemática, geometria, engenharias, arquitectura, náutica,...) mas também na arte, mobiliário, vestuário, ou nos esforços de regulação e formatação metrológica que a Coroa Portuguesa desenvolveu a partir do reinado de D. Manuel. Seria de esperar, portanto, que os objectos cerâmicos, na sua maioria intimamente vinculados às vivências do quotidiano, compreendendo aqui a modelação na olaria pelos artesãos, não encerrassem pressupostos genericamente análogos.

A vertente de trabalho arqueológico quantitativo sobre as dimensões, proporção e volume dos objectos cerâmicos modernos de contextos arqueológicos portugueses encontra-se, todavia, ainda num estádio incipiente. De facto, no interior de uma mesma morfologia encontram-se modelos de diversa envergadura, mostrando não só que no interior das olarias está em acção uma modelação, como essa modelação encerrará muitas vezes potencial significado a nível utilitário. Retomando o trabalho sobre o contexto formado nos inícios do séc. XVIII da Rua dos Correeiros (Lisboa), já citado acima (Ferreira et al., no prelo), a observação dos registos cumulativos dos EVE apresentados de acordo com a sua distribuição pelos diversos em raios de formas muito correntes de "cerâmica fosca de barro vermelho", de fabrico lisboeta, permite ler a existência de uma atracção por 3 e 4 módulos de raio definidos em função das variantes formais de panela, 5 para os testos, 4 nas caçoilas de bordo espessado, ao passo que nas de bordo em bisel se não constatou igual distinção, por fim, nos tachos se discernem 4 módulos distintos. Por conseguinte, a dimensão assume-se como essencial logo ao nível da primeira tarefa na abordagem da cerâmica, o trabalho classificatório, com as consequências implícitas ao nível da própria definição tipológica (Figura 2).

\section{CONSIDERAÇÕES FINAIS}

Os focos de interesse mais tradicional no âmbito disciplinar, casos das conexões entre geografias distantes, ou da aferição de status social e económico mediante a presença contextual das cerâmicas, nomeadamente as exógenas facultadas pelo incremento das relações à distância que se desenvolvem durante a expansão e o colonialismo europeus, poderão beneficiar largamente dos métodos quantitativos, ultrapassando o nível elementar de presença/ausência, ou situando na devida proporção as várias categorias cerâmicas mediante uma avaliação global sólida.

É certo que no âmbito da Arqueologia Moderna pesa o inevitável fascínio das aludidas ligações proporcionadas pela "primeira globalização", como as ocorrências asiáticas da porcelana, céladon, "thai jars" e potes martabã, ou o volume das importações de requintadas elaborações oleiras europeias, designadamente as italianas, holandesas e germânicas. Mas, e porque essa constitui uma das principais virtualidades da Arqueologia Moderna, que tem ao seu dispor a documentação, é imperioso que no discurso arqueológico disciplinar a narrativa seja, não só mais sólida de um ponto de vista metodológico, como mais informada. A esse propósito é quase irresistível invocar os preços dos bens em Vila Viçosa constantes do inventário produzido após o falecimento em 1563 do $5^{\circ}$ Duque de Bragança, D. Teodósio I, trabalhado para as matérias que mais interessam aqui por Joana Torres e André Teixeira (2018, p.326 e gráfico 25.1): nele, um “prato de Veneza” é avaliado em 20 reais, um "de Pisa" 65, um em porcelana 50 , em estanho 40 , em prata 3222; um pote vidrado 20, uma panela vidrada 50, um pote Martabã 400, um copo de vidro 50; ou contrastar os preços de um vaso empedradro de Badajoz, avaliado em 3 reais, com os 150 de um de Estremoz! Esta é apenas uma bem evocativa referência às potencialidades proporcionadas pelo cruzamento da informação altamente qualificada constante na documentação com o dado arqueológico, permitindo situar com precisão à época todo o contorno económico dos objectos mencionados e que ocorrem nos contextos modernos.

Como procurámos mostrar ao longo do presente texto, o refinamento metodológico na abordagem das cerâmicas que implica a quantificação, comporta vantagens evidentes ao nível da produção do discurso sobre as cerâmicas. Convém destacar aqui que, como afirmámos antes, o objectivo não é tanto o do apuramento da atribuição cronológica, ou do aprofundamento discriminatório na elaboração tipológica, como também não visa apenas a verificação de padrões, tendências, assimetrias ou distribuições: em última análise o que se persegue são as 
inferências que a partir daquelas observações e da produção de indicadores se podem elaborar, transportando a disciplina para outro nível da sua praxis, e facultando as ferramentas que permitem analisar comparativamente distintos contextos, quadros e geografias, e as inferências que, por seu turno, a partir daí se poderão de igual modo produzir.

\section{BIBLIOGRAFIA}

ALMEIDA, Mariana (2013) - As cerâmicas de importação do convento de Setúbal: Majólicas italianas e porcelana chinesa. In José Morais Arnaud, Andrea Martins e César Neves (coord.) - Arqueologia em Portugal: 150 anos. Lisboa: Associação dos Arqueólogos Portugueses (AAP), pp.1155-1162.

ARCELIN, Patrick; TUFFREAU-LIBRE, Marie (dir.) (1998) - La quantificacion des céramiques. Conditions et protocole. Ates de la table ronde du Centre Archéologique Européen du Mont Beuvray (Glux-en-Glenne, 7-9 avril 1998). Glux-enGlenne: Centre Archéologique Européen du Mont Beuvray (Colletion Bibrate, n.ำ 2).

BARCLAY, Keneth; BIDDLE, Martin; ORTON, Clive (1990) - The chronological and spatial distribution of the objects. In Martin Biddle (dir.) Object and economy in medieval Winchester. Artefacts from Medieval Winchester. Oxford: Clarendon Press (col. Winchester Studies, 1), pp. 42-73.

BARGÃO, André (2015) - Vivências do quotidiano do Hospital Real de Todos-Os-Santos (Lisboa). Os contextos do poço SE do claustro NE. Lisboa: Faculdade de Ciências Sociais e Humanas (Dissertação de Mestrado).

BARKER, David; MAJEWKI, Teresita (2014) - Chapter 12. Ceramic studies in historical archaeology. In Dan Hicks e Mary Beaudry (eds.), The Cambridge companion to Historical Archaeology ( $4^{\underline{a}}$ Ed.). Cambridge: Cambridge University Press, pp. 205-231.

BINFORD, Lewis (1968) - New Perspectives in Archaeology. Chicago: Aldine Press.

CASIMIRO, Tânia (2010) - Faiança Portuguesa nas Ilhas Britânicas (dos finais do século XVI aos inícios do século XVIII). Lisboa: Faculdade de Ciências Sociais e Humanas da Universidade Nova de Lisboa (Dissertação de doutoramento).

CASIMIRO, Tânia (2013) - Faiança portuguesa: datação e evolução crono-estilística. In Revista portuguesa de Arqueologia, n.. 16. Lisboa: Igespar, pp. 351-367.

CASTRO, Fernando; DÓRDIO, Paulo; TEIXEIRA, Ricardo (1998) - 200 anos de cerâmica na Casa do Infante: do séc. XVI a meados do séc. XVIII. In João Diogo e Hélder Chilra Abraços (Eds.) Actas das II Jornadas Cerâmica Medieval e Pós-Medieval. Métodos e resultados para o seu estudo (Tondela, 22-25 de Março de 1995). Tondela: Câmara Municipal de Tondela, pp. 223-230.
CLARKE, David (1968) - Analytical Archaeology. London: Methuen.

CLARKE, David (1973) - Archaeology: the loss of innocence. Antiquity. Cambridge: 47. pp. 6-18.

DESBAT, Alain (1990) - Les bons comptes font les bons amis ou la quantification des céramiques. In SFECAG Actes $d u$ Congès de Mandeure-Mathay. Mandeure-Mathay: Société Française d'Études de Céramique Antique en Gaule, pp. 131-135.

DIOGO, António Manuel Dias; TRINDADE, Laura (1995) - Cerâmicas de Lisboa provenientes de contextos datados : materiais de uma lareira de cozinha destruída pelo Terramoto de 1755. In João Manuel Diogo e Hélder Chilra Abraços (eds.), Actas das ias. Jornadas de Cerâmica Medieval e Pós- Medieval. Métodos e Resultados para o seu Estudo (Tondela, 1991). Tondela: Câmara Municipal de Tondela, pp. 163-170.

DÓRDIO, Paulo (1997/1998) - Como pôr ordem em 500 ooo fragmentos de cerâmica? Ou discussão da metodologia de estudo da cerâmica na intervenção arqueológica da Casa do Infante (Porto). In Olaria: Estudos Arqueológicos, Históricos e Etnológicos, $2^{\underline{a}}$ Série, $\mathrm{n}^{\circ} 2$ (duplo). Barcelos: Museu da Olaria, pp. 115-125.

FENTRESS, Elisabeth; PERKINS, Philip (1988) - Counting African Red Slip Ware. In A. Mastino (Ed.), L'Africa romana: Atti del V convegno di studi (Sassari 11-13 dicembre 1987). Sassari: Ed. Gallizi, pp. 205-214.

FERREIRA, Sara (2015) - O sítio do forte de São Paulo: estudo arqueológico da Ribeira Ocidental de Lisboa na época moderna. Lisboa, Faculdade de Ciências Sociais e Humanas (Dissertação de Mestrado).

FERREIRA, Sara da Cruz; BARGÃO, André; SILVA, Rodrigo Banha da; TORRES, Joana Bento; TEIXEIRA, André (no prelo) - Um contexto dos inícios do século XVIII da Rua dos Correeiros (Baixa de Lisboa): revisão crítica dos dados da Sondagem 14 (1991). In Actas dos II Encontros de Arqueologia de Lisboa. Lisboa: Departamento de Património Cultural, Centro de Arqueologia de Lisboa.

FERREIRA, Sara; BARGÃO, André (2016)-O Sítio do Forte de São Paulo: Estudo Arqueológico da Ribeira Ocidental de Lisboa na Época Moderna". In Inês Pinto Coelho, Luís Serrão Gil, (eds.), Entre ciência e cultura: da interdisciplinaridade à transversalidade da arqueologia. Actas das VIII Jornadas de Jovens em Investigação Arqueológica. Lisboa: CHAM-Centro de História d'Aquém e d'Além Mar (col. ArqueoArte, n. .4 ), pp. 243-250.

FERREIRA, Sara; NEVES, César; MARTINS, Andrea; TEIXEIRA, André (2017) - Fragmentos da Mesa Nobre e de uma cidade em transformação: porcelana chinesa em contexto de terramoto da Praça do Comércio (Lisboa, Portugal). In Ana Caessa, Cristina Nozes, Isabel Cameira e Rodrigo Banha da Silva (coord.), I Encontro de Arqueologia de Lisboa. Uma cidade em escavação (Teatro Aberto, 26, 27 e 28 de Nov. de 2015). 
Lisboa: Departamento de Património Cultural, Centro de Arqueologia de Lisboa, pp. 459-477.

FLETCHER, Lock (1991) - Digging numbers. Elementary satistics for archaeologists. Oxford: Oxford University (col. Oxford University Comitee for Archaeology monograph, 33).

GOMES, Paulo Dórdio; SILVA, António Manuel S. P.; TEIXEIRA, Ricardo; COUTO, Marcos; RODRIGUES, Miguel (2018) - Louça vermelha de Aveiro e de Ovar: ensaio de uma síntese atualizada. In FRANÇA, A.; PEREIRA, G.; ELVAS, R. (coord.), 3.7. Olaria de Ovar - Catálogo da Exposição. Ovar: Câmara Municipal de Ovar, pp. 4-43.

GOMES, Rosa Varela (2012) - A Arqueologia da Idade Moderna em Portugal - contributos e problemáticas. In O Arqueólogo Português, Série V, n.ํㅜ 2. Lisboa: Museu Nacional de Arqueologia, pp. 13-75.

HODDER, Ian (Ed.) (1982) - Symbolic and Structural Archaeology. Cambridge: Cambridge University Press.

HODDER, Ian; HUTTON, Scott (2003) - Reading the Past: Current Approaches to Interpretation in Archaeology ( $3^{\underline{a}}$ ed.). Cambridge: Cambridge University Press.

HUSI, Philippe (2001) - Quantification et datation en céramologie (Le nombre minimum d'indivius: la technique de quantification la mieux adaptée à la datation des contextes archéologiques à partir de l'ensemble de Tours. Tours: Université de Tours, Laboratoire Archéologie et Territoirs (col. Les Petits Cahiers d'Anatole, n.․ 6).

LAMOTTA, Vincent M; SCHIFFER, Michael B. (2005) Archaeological formation processes. In Colin Renfrew e Paul Bahn, Archaeology. The key concepts. Londres e Nova Iorque: Routledge, pp. 121-126.

MADSEN, Torsten (dir.) 1988 - Numerical approaches in Scandinavian Archaeology. Jutland: Aarhus University (Jutland Archaeoloical Society publications, 21).

OLIVEIRA, Filipe (2012) - Espólio de Idade Moderna, proveniente do Beco das Barrelas, Alfama, Lisboa. Lisboa: Faculdade de Ciências Sociais e Humanas (Dissertação de Mestrado).

ORTON, Clive (1975) - Quantitative pottery studies: some progress, problems and prospects. In Science and Archaeology, n. ${ }^{\circ} 16$. Stoke-on-Trent: Research Centre for computer Archaeology, pp. 30-35.

ORTON, Clive (1979) - Dealing with the pottery from a 6 oo acre urban site. In Martin Millet (Ed.) Pottery and the Archaeologist. Londres: Institute of Archaeology (col. Institute of Archaeology Occasional Publications, 4), pp. 61-71.

ORTON, Clive (1980) - Mathematics in Archaeology. Cambridge: Collins Publications (col. Cambridge Manuals in Archaeology).

ORTON, Clive (1982)- Computer simulation experiments to assess the perfomance of measures of quantity of pottery. In World Archaeology, 14, n. ${ }^{\circ}$, pp. 1-20.
ORTON, Clive (1989) - An introduction to the quantification of assemblages of pottery. In Journal of Roman Pottery Studies, n. ํㅜㄹ. Oxford: Oxbow Books, pp. 94-97.

ORTON, Clive (1993) - How many pots make five? - an historical review of pottery quantification. In Archaeometry, vol. 35-2. Oxford: Oxford University, pp. 169-184.

ORTON, Clive; HUGHES, Michael (2013) - 5. Quantification In Pottery in Archaeology (2 $2^{\underline{a}}$ Ed.). Cambridge: Cambridge University Press (col. Cambridge Manuals in Archaeology), pp. 203-218.

ORTON, Clive; TYERS, Paul; VINCE, Alan (1993) - Pottery in Archaeology. Cambridge: Cambridge University Press (col. Cambridge Manuals in Archaeology).

PEARCE, Jacqueline (1992) - Border Wares. In Post-Medieval Pottery in London 1500-170o, vol. I. London: Museum of London.

PEÑA, J. Theodor (2007) - Roman Pottery in the Archaeological Record. Cambridge: Cambridge University Press.

REAL, Manuel L.; DÓRDIO, Paulo; TEIXEIRA, Ricardo; MELO, Rosário (1995) - Conjuntos cerâmicos da intervenção arqueológica da Casa do Infante, Porto: elementos para uma sequência longa (Sécs. IV-XIX). In João Manuel Diogo e Hélder Chilra Abraços (Eds.), Actas das 1as. Jornadas de Cerâmica Medieval e Pós-Medieval. Métodos e Resultados para o seu Estudo (Tondela, 1991). Tondela: Câmara Municipal de Tondela, pp. 171-186.

REAL, Manuel Luís; GOMES, Paulo Dórdio; TEIXEIRA, Ricardo; SILVA, António Manuel (2015) - A investigação científica na Casa do Infante. In Amândio de Barros (coord.), Os Descobrimentos e as origens da convergência global. Porto: Câmara Municipal do Porto, Associação para a Divulgação da Cultura de Língua Portuguesa, pp. 325-333.

REMOLÁ VALLVERDÚ, Josep Antón (200o) - Las ánforas tardo-antiguas en Tarraco (Hispania Tarraconensis) Siglos IV-VII d.C. Barcelona: Universitat de Barcelona (Col.lecció Instrumenta, $\mathrm{n} .{ }^{\circ} 7$ ).

SEBASTIAN, Luís (2010) - A Produção Oleira de Faiança em Portugal (Séculos XVI-XVIII). Lisboa: Faculdade de Ciências Sociais e Humanas da Universidade Nova de Lisboa. (Dissertação de Doutoramento).

SHANKS, Michael; TILLEY, Christopher Y. (1992) - ReConstructing Archaeology. Theory and Practice. New Studies in Archaeology ( $2^{\underline{\underline{a}}}$ ed.). London e New York: Routledge.

SHENNAN, Stephen (1997) - Quantifying Archaeology. Edinburgh: Edinburgh University Press.

SILVA, Ricardo Costeira da (2013) - Primeira abordagem a um depósito moderno no Antigo Paço Episcopal de Coimbra (Museu Nacional de Machado de Castro): a cerâmica desde meados do século XV à consolidação da Renascença. In André Teixeira e José Bettencourt (coords.), Velhos e Novos Mundos, vol. II. Lisboa: Centro de História de Além-Mar (col. Estudos de Arqueologia Moderna, 1), pp. 877-89o. 
SILVA, Ricardo Costeira da (2016b) - The faience of the $2^{\text {nd }}$ half of the 16t century at the Episcopal Palace of Coimbra (Portugal). In Rosa Varela Gomes, Tânia Casimiro e Mário Varela Gomes (eds.), Proceedings of the $\mathrm{I}^{\mathrm{st}}$ International Conference of Portuguesa Faience (1 $6^{\text {th }}$ to $19^{\text {th }}$ centuries). S.l: Instituto de Arqueologia e Paleociências, pp. 181-188.

SILVA, Ricardo Jorge Costeira da (2016a) - O Museu Nacional de Machado de Castro: um ensaio de arqueologia urbana em Coimbra: do fórum augustano ao paço episcopal de Afonso de Castelo Branco. Coimbra: Faculdade de Letras da Universidade de Coimbra (dissertação de doutoramento).

SILVA, Rodrigo Banha da (2005) - As «marcas de oleiro» da terra sigillata da Praça da Figueira (Lisboa): uma contribuição para o conhecimento da economia de Olisipo (séc. I a.C. - séc. II d.C.). Braga: Universidade do Minho, Instituto de Ciências Sociais (Dissertação de mestrado).

SIMÃO, Inês; PINTO, Marina; PIMENTA, João; FERREIRA, Sara da Cruz; BARGÃO, André; SILVA, Rodrigo Banha da (no prelo) - Os cachimbos dos séculos XVII e XVIII do Palácio Mesquitela e Convento dos Inglesinhos (Lisboa). In José Morais Arnaud e Andreia Martins (eds.), Actas do III Congresso da Associação dos Arqueólogos Portugueses. Libsoa: Associação dos Arqueólogos Portugueses.

T1 NMI (477)

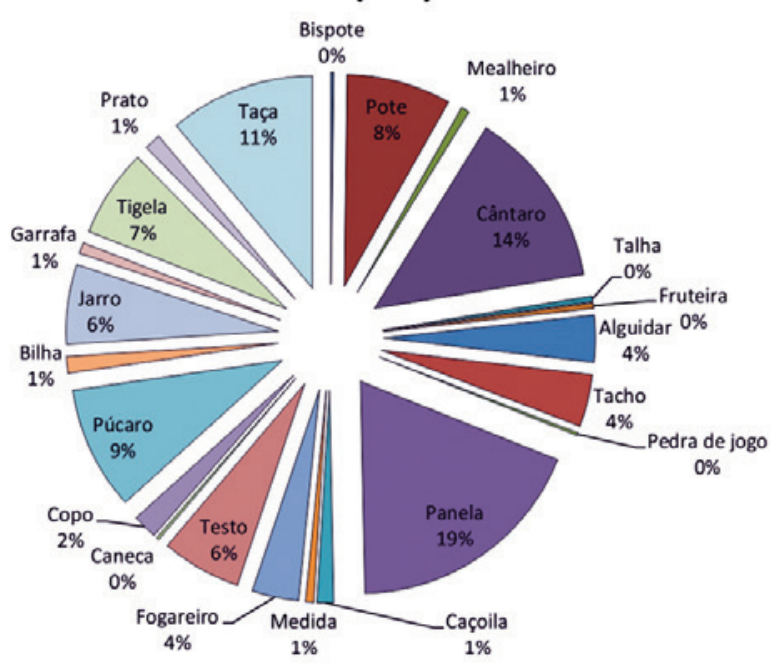

SPAULDING, Albert C. (1953) - "Statistical techniques for the discovery of artifact types". In American Antiquity. Vol. 18-4: pp. 305-313.

TORRES, Joana Bento; TEIXEIRA, André; (2018) - Capítulo 25. Com o lume aceso. As cozinhas do Paço Ducal no século XVI. In Jessica Hallet e Nuno Senos (coord.), De Todas as partes do mundo. O património do $5^{\circ}$ Duque de Bragança, D. Teodósio I, vol.I, Estudos. Lisboa: CHAM-Centro de Humanidades, Tinta da China, pp. 317-329.

TRIGGER, Bruce (1989)- A History of Archaeological Thought. New York: Cambridge University Press.

TRINDADE, Laura; DIOGO, A.M. Dias (2003) - Cerâmicas de Barro Vermelho de Entulhos do Terramoto de 1755 Provenientes da Sondagem 14 da Rua dos Coreeiros, em Lisboa.

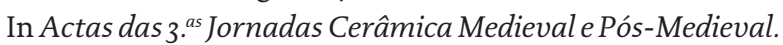
Métodos e resultados para o seu estudo. Tondela: Câmara Municipal de Tondela, pp. 285-293.

T1 EVE (191)

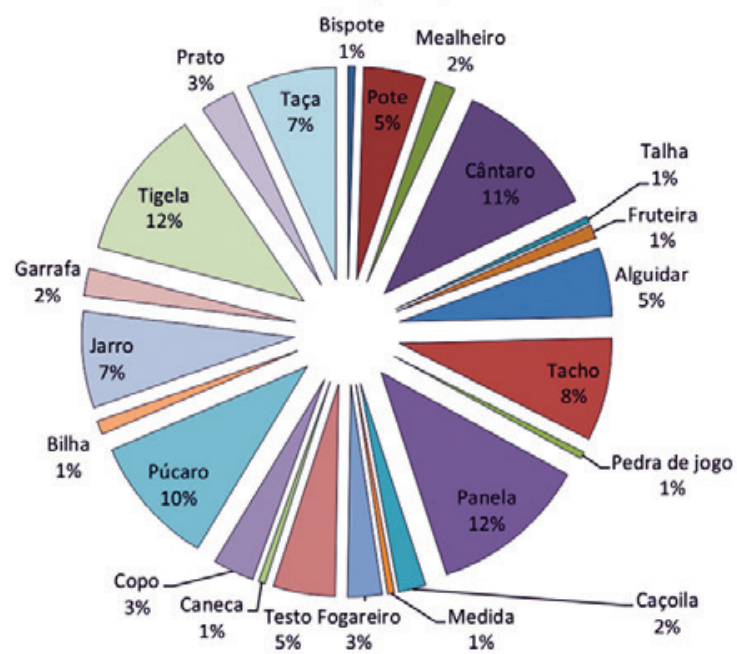

Figura 1 - Quantificação do conjunto cerâmico de um poço medieval nas traseiras do Hospital Real de Todos-os-Santos (Lisboa), segundo NMI e EVE. 


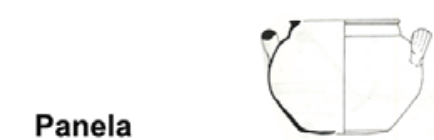

\begin{tabular}{|r|r|r|r|r|}
\hline \multirow{2}{*}{ Raio } & Exvertido & \multicolumn{3}{|c|}{ Invertido } \\
\cline { 2 - 5 } & Quadrangular & Quadrang & Semi-circular & Triangular \\
\hline 4 & & & & $10 \%$ \\
\hline 5 & & & $10 \%$ & $5 \%$ \\
\hline 5,5 & $12 \%$ & $22 \%$ & & \\
\hline 6 & $10 \%$ & $176 \%$ & $72,50 \%$ & $175,50 \%$ \\
\hline 6,5 & & $87 \%$ & $43 \%$ & \\
\hline 7 & $23 \%$ & $365 \%$ & $129,50 \%$ & $210,50 \%$ \\
\hline 7,5 & & $40 \%$ & $27 \%$ & $52,50 \%$ \\
\hline 8 & $8 \%$ & $223,50 \%$ & $240,50 \%$ & $286,50 \%$ \\
\hline 8,5 & & $90,50 \%$ & $47,50 \%$ & $115 \%$ \\
\hline 9 & $6 \%$ & $248 \%$ & $118,50 \%$ & $202 \%$ \\
\hline 9,5 & & & & $105 \%$ \\
\hline 10 & & $79 \%$ & $120,50 \%$ & $153,00 \%$ \\
\hline 10,5 & & & & $12,50 \%$ \\
\hline 11 & & & $60,50 \%$ & $28 \%$ \\
\hline 13 & & & & $19 \%$ \\
\hline
\end{tabular}

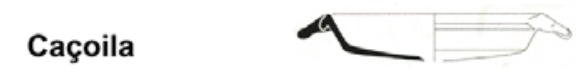

\begin{tabular}{|c|c|c|c|c|}
\hline \multirow[b]{2}{*}{ Raio } & \multicolumn{2}{|c|}{ Bisel } & \multicolumn{2}{|c|}{ Espessado } \\
\hline & Semi-circu & Triangular & Semi-circ & Triangular \\
\hline 6 & $12 \%$ & & & \\
\hline 7 & & & $10 \%$ & \\
\hline 9 & $32 \%$ & & $67,50 \%$ & \\
\hline 9,5 & $16 \%$ & & & \\
\hline 10 & $24 \%$ & & $131 \%$ & \\
\hline 11 & $13 \%$ & $2,50 \%$ & $183,50 \%$ & \\
\hline 12 & $21 \%$ & & $147,50 \%$ & \\
\hline 12,5 & $32,50 \%$ & & & \\
\hline 13 & & & $182 \%$ & \\
\hline 14 & $9 \%$ & & $75 \%$ & $7 \%$ \\
\hline 15 & $12 \%$ & & $30,50 \%$ & \\
\hline 16 & & & $39,50 \%$ & \\
\hline 17 & & & $20 \%$ & \\
\hline 19 & & $7 \%$ & & \\
\hline 8 & & & $17,50 \%$ & \\
\hline
\end{tabular}

\section{Tacho}

Testo

\begin{tabular}{|r|r|}
\hline Raio & \\
\hline 3,5 & $35,00 \%$ \\
\hline 4,5 & $10 \%$ \\
\hline 5 & $62,50 \%$ \\
\hline 5,5 & $20 \%$ \\
\hline 6 & $92 \%$ \\
\hline 6,5 & $174,50 \%$ \\
\hline 7 & $239 \%$ \\
\hline 7,5 & $34,50 \%$ \\
\hline 8 & $337,50 \%$ \\
\hline 8,5 & 36,5 \\
\hline 9 & $162,50 \%$ \\
\hline 10 & $120,50 \%$ \\
\hline 11 & $20 \%$ \\
\hline 12 & $7,50 \%$ \\
\hline
\end{tabular}

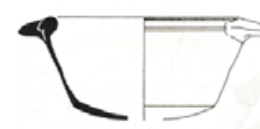

\begin{tabular}{|r|r|l|}
\hline \multirow{2}{*}{ Raio } & Espessado & Bisel \\
\cline { 2 - 3 } & Semi-cir & Semi-cir \\
\hline 5 & $10 \%$ & \\
\hline 7 & $46 \%$ & \\
\hline 8 & $105 \%$ & \\
\hline 8,5 & $10 \%$ & \\
\hline 9 & $239,50 \%$ & \\
\hline 9,5 & $208 \%$ & \\
\hline 10 & $375 \%$ & $18,50 \%$ \\
\hline 10,5 & $42,50 \%$ & \\
\hline 11 & $146 \%$ & $5 \%$ \\
\hline 11,7 & $100 \%$ & \\
\hline 12 & $219,50 \%$ & \\
\hline 12,5 & $75 \%$ & \\
\hline 13 & $139,50 \%$ & \\
\hline 13,5 & $19 \%$ & \\
\hline 14 & 172,5 & \\
\hline 16 & $57 \%$ & \\
\hline 17 & $7,50 \%$ & \\
\hline 18 & $15 \%$ & \\
\hline 19 & $7,50 \%$ & \\
\hline 22 & $18 \%$ & \\
\hline
\end{tabular}

Figura 2 - Contabilização comulativa dos EVE de quatro formas de "cerâmica fosca de barro vermelho" de um contexto de inícios do século XVIII da Rua dos Coreeiros (Lisboa). 


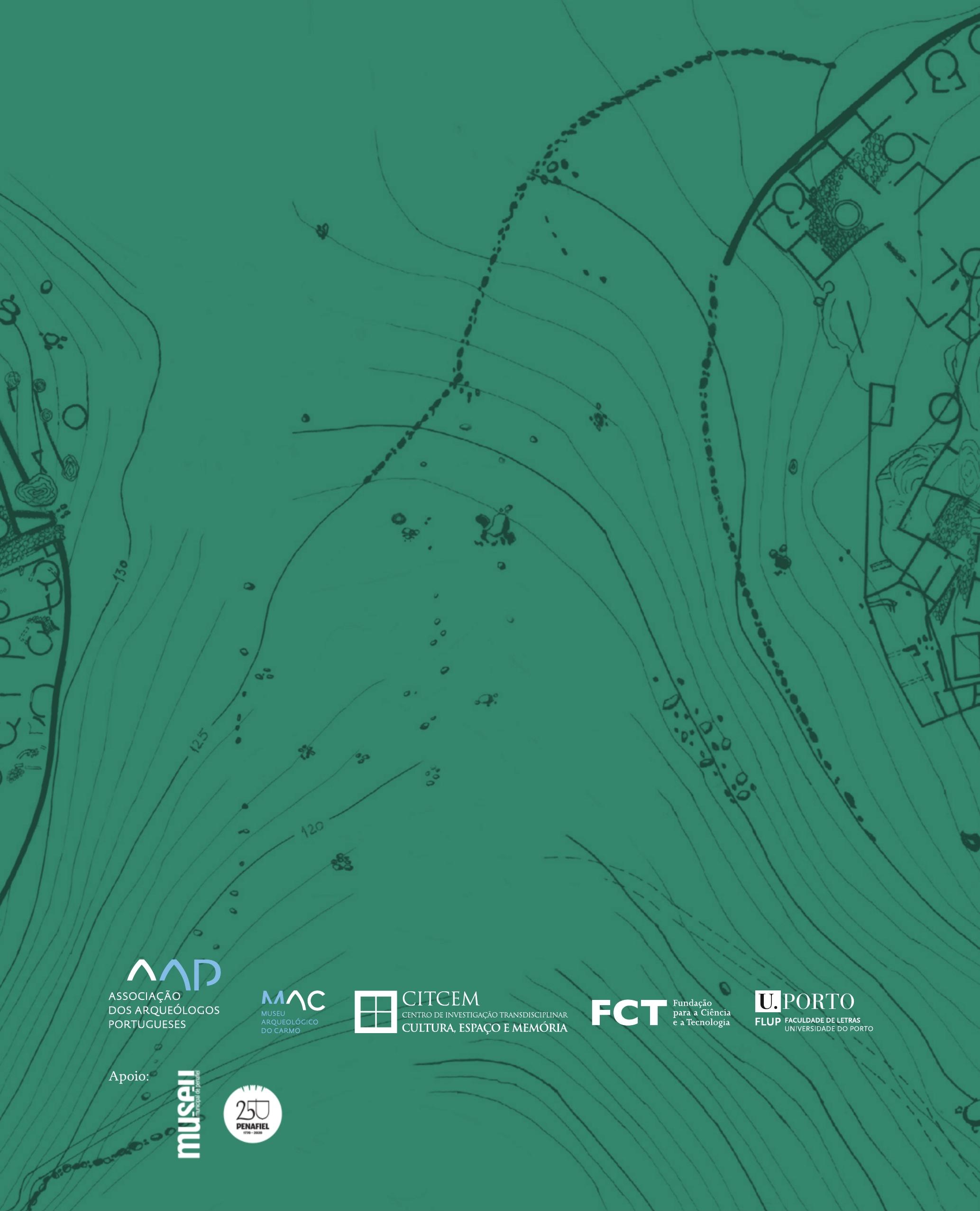

